\title{
Lost in translation? Ways for environmental sciences to communicate about risk and research
}

\author{
Thomas-Benjamin Seiler ${ }^{1 *}$, Magnus Engwall ${ }^{2}$ and Henner Hollert ${ }^{1}$
}

\begin{abstract}
This editorial is an introduction to a paper series on the communication of environmental sciences and risk, developed as an idea from a session at the 6th SETAC World Congress 2012.

Environmental sciences are at the heart of what people affect in their daily lives: environmental quality, safe food, clean air, fresh water - and hence crucial for sound public health. Why aren't we in their daily minds? How should we communicate to get there? Communication means to convey meaningful information to create shared understanding. But only a minority of scientists have knowledge about the principles of science communication and even less than these are certainly up-to-date with modern communication concepts. The paper series "Lost in translation? Ways for environmental sciences to communicate about risk and research" collates views and perspectives on science and risk communication from different angles to initiate a broader discussion on the communication about research findings in environmental sciences.
\end{abstract}

Keywords: Environment, Science, Risk, Public, Communication, Understanding, Ivory tower

\section{Dear reader,}

Being an environmental scientist, have you lately tried to explain to a layman what you are researching? Or being from the general public, have you had difficulties to understand what someone from environmental sciences was telling you? Despite a far more open scientific community than - let's say - during the middle ages, academia and the public still seem to live in two different worlds.

\section{Science communication evolved}

In principle, science communication already came a long way. In the 1950s research was all science fiction. Expectations of what is possible were led and facilitated through pictures from novels, radio plays and movies. But the more complex and powerful scientific findings and technological achievements got, the more scepticism spread among the common people. The scientific community and stake holders tried to face this development by large-scale information campaigns. However, it finally became evident that interest for and acceptance of scientific research is not a matter of sufficient knowledge

\footnotetext{
* Correspondence: seiler@bio5.rwth-aachen.de

${ }^{1}$ Institute for Environmental Research, RWTH Aachen University,

Worringerweg 1, 52074, Aachen, Germany

Full list of author information is available at the end of the article
}

through comprehensive explanation [a so called „deficit model“; e.g. ] [1]. Rather personal concernment as a result of emotions and a code of values drives excitement for scientific topics (Figure 1). As a consequence, science communication entered the PUSH phase („public understanding of science and humanities") meaning to effectively establish (positive) understanding of scientific research within the public. Since the internet completely changed the way information is consumed, science communication once more will adapt to new conditions, probably becoming very much more interactive and, thus, a unique participatory process.

Only a minority of scientists have knowledge about the principles of science communication and even less than these are certainly up-to-date with modern communication concepts. A large amount of dissemination activities of research findings is still based on a scientist's monologue with detailed explanations. On the other hand, the largest part of science news consumers know little to nothing about how scientific research happens. Even if they acquire knowledge through the different available info/edutainment formats, this view of science is generally biased by the pictures the media use to portray research and which often have little in common with reality. Hence, though communication of science to 


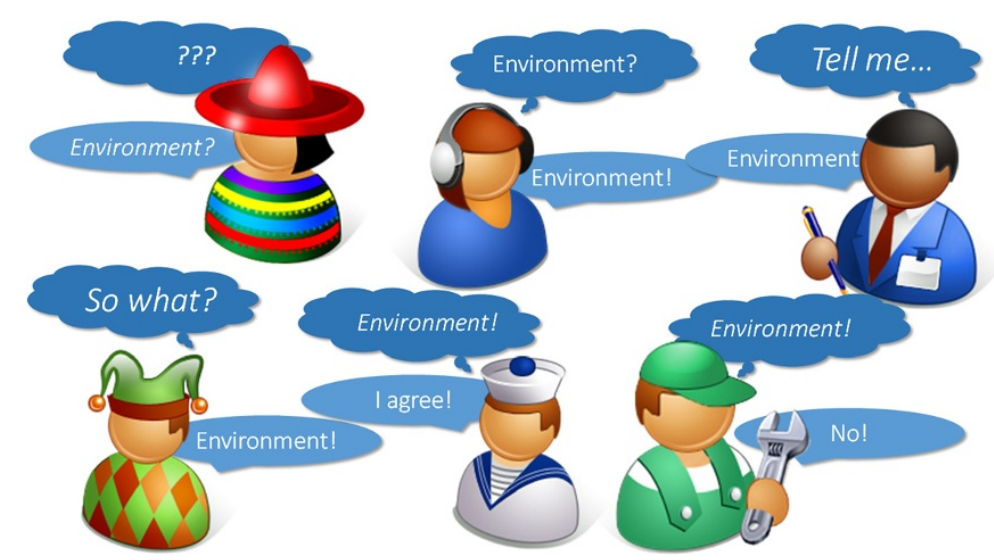

Figure 1 Understanding of science is driven and influenced by personal concernment as a result of emotions and a code of values. This in particular pertains to environmental sciences being a subject of growing common interest.

the public strongly increased within the last decades, research still seems to be a mystery place.

\section{Messages from the ivory tower}

'Ivory Tower' as a term is generally used to depict intellectuals that are disconnected from everyday life and reality. Let's imagine there is an ivory tower that is completely carved from ivory, every single bit. The walls, the floors, the stairs, the doors and even the furniture. Inhabitants of this tower for sure know how it feels to live surrounded by ivory. On the other hand, they do not have much impression of how life is like without it.

The metaphor of science living in an ivory tower is therefore not only describing a world locked away, but portrays also the fact of different linguistic, social, habitual properties compared to the outside. So even if universities and research institutions become more open, scientists on the one side and regulators, journalists, policymakers as well as the common people on the other might face difficulties to communicate as they do not have very much in common. Connections from the laboratory to the public of course exist, via, e.g., press relations offices, news on institute web sites, or reception of important findings in newspapers. However, the crucial question is: what is perceived by the public that can generate impact?

Communication means to convey meaningful information to create shared understanding. If messages from environmental science are not suitable to produce public endorsement, we remain in the ivory tower despite all connections there might be. This demands easily comprehensible communication and also for subsequent confirmation of the right understanding. As environmental sciences live through a concern about the environment as a whole, disconnection from our outside is more than just a typical academic characteristic. In the end it is a complete failure of our fundamental intentions.
Consequently, to truly escape from the ivory tower it is not sufficient for environmental science to merely contact the public outside but to effectively and sustainably distribute its findings for a safer and healthier environment.

\section{Building the basis for communication}

This paper series was developed as an idea from a session at the world congress 2012 of the Society of Environmental Toxicology and Chemistry (SETAC) in Berlin, Germany (cf. Video link in Figure 2), and collates views and perspectives on science and risk communication from different angles. The session already showed that emotions play a key role. Whilst scientists are dedicated to sound reasoning and rational thinking, the receiving public care intuitively about their fears and desires. This series should initiate a broader discussion on the communication about research findings in environmental sciences.

Hunka and co-workers and Heidmann \& Milde address one of the crucial questions of science communication:

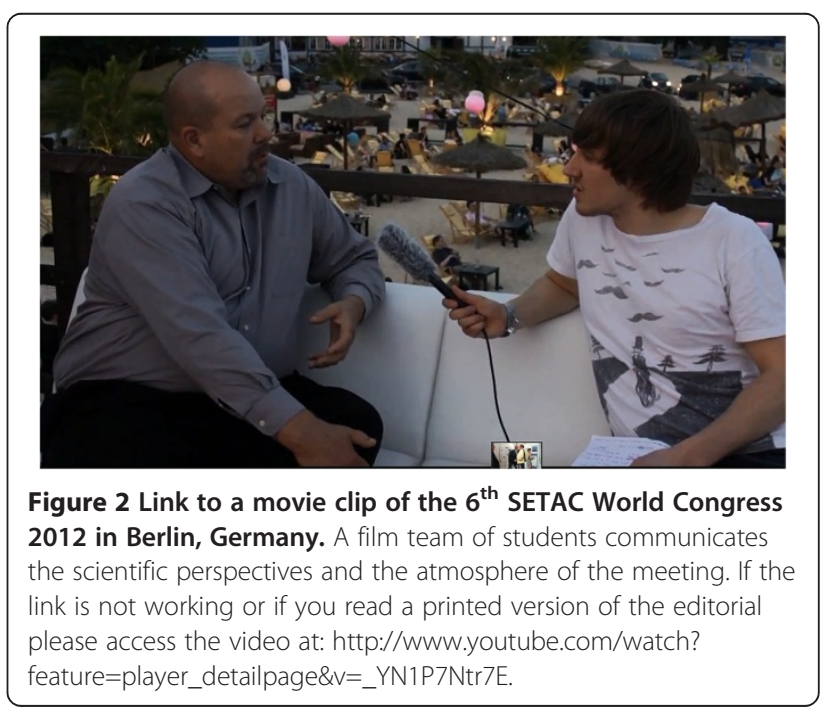


how to keep credibility while allowing uncertainty and disagreement, the two most vital characteristics of the scientific process. Descending from this rather intradisciplinary view and, thus, the ivory tower to more applied topics, Klaschka \& Rother and Castellani and co-workers report on practical cases of science communication for personal care products, fine particulate matter emissions and renewable energy, respectively. The contributions by Seiler and co-workers, Kübel and co-workers and Rinn and coworkers [2] describe possible approaches towards leaving the mystery place and eventually allow the society to get 'a feeling of ivory'.

\section{Present contributions to the series}

Castellani V, Piazzalunga A, Sala S: Research findings and decision making: the case of renewable energy.

Heidmann I, Milde J: Evaluating the communication about nanoparticle research: How scientists and science journalists deal with uncertainty.

Hunka A, Palmqvist A, Forbes VE: Scientific consensus and risk communication. How does the public react when scientists disagree?

Klaschka U, Rother H-A: "Read this and be safe!" Comparative regulatory processes for communicating risks of personal care products to European and South African consumers.

Kübel W, Zielke H, Hollert H: Knowing how to know ecotoxicologists learn to communicate with the mass media.

Rinn A, Kivelitz C, Berghahn R: See it with my eyes! Artificial stream research communicated by an artist.

Seiler T-B, Engwall M, Hollert H: Know your audience! Science communication as a directed marketing effort.

\section{Call for papers}

Environmental Sciences Europe (ESEU) will be the place for this process and the discussion about possible strategies. The journal understands itself as a bridge between scientists and all stake holders including the general public. Already some previous contributions in ESEU addressed risk communication in different fields e.g. [3,4].

Hence, this series has just landed. We cordially invite all colleagues who feel they can contribute to the topic to submit a manuscript to ESEU with reference to this series. In particular all contributors to the session "Bridging the gap between risk perception and ecotoxicology research - how can we communicate to improve our outreach?" at the SETAC Europe Annual mMeting 2013 in Glasgow, Scotland, UK, are invited to consider publication of their studies and opinions in ESEU.

\section{Consent}

Written informed consent was obtained from the persons for publication of this report and any accompanying images.

\section{Abbreviations \\ PUSH: Public Understanding of Science and Humanities; SETAC: Society of Environmental Toxicology and Chemistry.}

\section{Competing interests}

The authors declare that they have no competing interests.

\section{Authors' contributions}

T-BS, who is responsible for the general design of the session at the SETAC World congress and the publication series, wrote the first draft of the manuscript. The other authors contributed specific aspects. All authors read and approved the final manuscript.

\section{Acknowledgements}

The authors thank Rada Bieberstein and Tilman Gocht from University of Tübingen, Germany, for vivid conversation and discussion about communication, which eventually lead to the idea for this series.

\section{Author details}

${ }^{1}$ Institute for Environmental Research, RWTH Aachen University, Worringerweg 1, 52074, Aachen, Germany. ²Department of Natural Science, Man-Technology-Environment, Research Centre (MTM), University of Örebro, 70182, Örebro, Sweden.

Received: 4 April 2013 Accepted: 5 April 2013

Published: 26 April 2013

\section{References}

1. Kahan DM, Braman D, Slovic P, Gastil J, Cohen G: Cultural cognition of the risks and benefits of nanotechnology. Nat Nano 2009, 4:87-90.

2. Rinn A, Kivelitz C, Berghahn R: See it with my eyes! Artificial stream research communicated by an artist. Environmental Sciences Europe 2013. accepted.

3. Schulte C, Tietjen L, Bambauer A, Fleischer A: Five years REACH - lessons learned and first experiences. I. an authorities' view. Environmental Sciences Europe 2012, 24:31.

4. Klaschka U: Dangerous cosmetics - criteria for classification, labelling and packaging (EC 1272/2008) applied to personal care products. Environmental Sciences Europe 2012, 24:37.

doi:10.1186/2190-4715-25-8

Cite this article as: Seiler et al:: Lost in translation? Ways for environmental sciences to communicate about risk and research. Environmental Sciences Europe 2013 25:8.

\section{Submit your manuscript to a SpringerOpen ${ }^{\odot}$ journal and benefit from:}

- Convenient online submission

- Rigorous peer review

- Immediate publication on acceptance

- Open access: articles freely available online

- High visibility within the field

- Retaining the copyright to your article

Submit your next manuscript at $>$ springeropen.com 